\title{
Correction to: Families in the COVID-19 pandemic: parental stress, parent mental health and the occurrence of adverse childhood experiences - results of a representative survey in Germany
}

\author{
Claudia Calvano $^{1}$ (D) $\cdot$ Lara Engelke $^{2} \cdot$ Jessica Di Bella $^{1} \cdot$ Jana Kindermann $^{1} \cdot$ Babette Renneberg $^{2} \cdot$ Sibylle M. Winter $^{1}$
}

Published online: 22 June 2021

๑) Springer-Verlag GmbH Germany, part of Springer Nature 2021

\section{Correction to: European Child \& Adolescent Psychiatry https://doi.org/10.1007/s00787-021-01739-0}

Due to a syntax error, the PHQ4-scores for parent mental health need to be corrected as follows: For the total PHQ scores, the sample mean is $M=2.52(\mathrm{SD}=2.63)$, for anxiety $M=1.14(\mathrm{SD}=1.42)$ and for depression $M=1.38$ ( $\mathrm{SD}=1.43)$. Accordingly, $n=134(13.1 \%)$ of the sample scored above the 95th percentile for the total score, $n=149$ (14.6\%) for anxiety and 178 (17.4\%) for depression.

The original article can be found online at https://doi.org/10.1007/ s00787-021-01739-0.

Claudia Calvano

claudia.calvano@charite.de

1 Department of Child and Adolescent Psychiatry,

Psychosomatics and Psychotherapy, Charité -

Universitätsmedizin Berlin, corporate member of Freie

Universität Berlin, Humboldt-Universität zu Berlin, and Berlin Institute of Health, Augustenburger Platz 1, 13353 Berlin, Germany

2 Department of Education and Psychology, Clinical Psychology and Psychotherapy, Freie Universität Berlin, Habelschwerdter Allee 45, 14195 Berlin, Germany
These scores are higher than reported in the original manuscript. The conclusions of the paper do not change, as these are still lower than reported in other studies.

The comparison with German reference scores is depicted in Fig. 2. The effect sizes of the comparison remain small (depression $d=0.31$; anxiety, $d=0.23$; total score $d=0.29$ ).

Furthermore, the correlations show minor changes (Table 3). Please find a revised Table 3 below.

Comparisons of the subgroups with an increase in ACES vs. decrease/no change do not change on the main result; effect sizes of the comparisons slightly increase. Please find the revised Figs. $4 \mathrm{c}$ and 5c below: 




Fig. 2 Comparison of PHQ-4 scores for depression, anxiety, and total score in our sample and in German normative data [21]. All between group differences were significant at $p<0.001$

Table 3 Correlation between the pandemic-related burden and parental outcomes

\begin{tabular}{|c|c|c|c|c|c|c|}
\hline & & 2 & 3 & 4 & 5 & 6 \\
\hline 1 & $\begin{array}{l}\text { Pandemic-related } \\
\text { parental burden }\end{array}$ & 0.352 & 0.434 & -0.279 & 0.340 & 0.329 \\
\hline 2 & Parental stress ${ }^{\mathrm{a}}$ & & 0.423 & -0.336 & 0.406 & 0.441 \\
\hline 3 & General stress & & & -0.461 & 0.583 & 0.571 \\
\hline 4 & Subjective health & & & & -0.444 & -0.433 \\
\hline 5 & Anxiety & & & & & 0.707 \\
\hline 6 & Depression & & & & & - \\
\hline
\end{tabular}

${ }^{\text {a}}$ Parental stress at time of the highest burden; for the subjective health rating, higher scores indicate better health, for the other outcomes, higher scores indicate higher burden, stress and symptoms. All correlations are significant with $p<0.001$
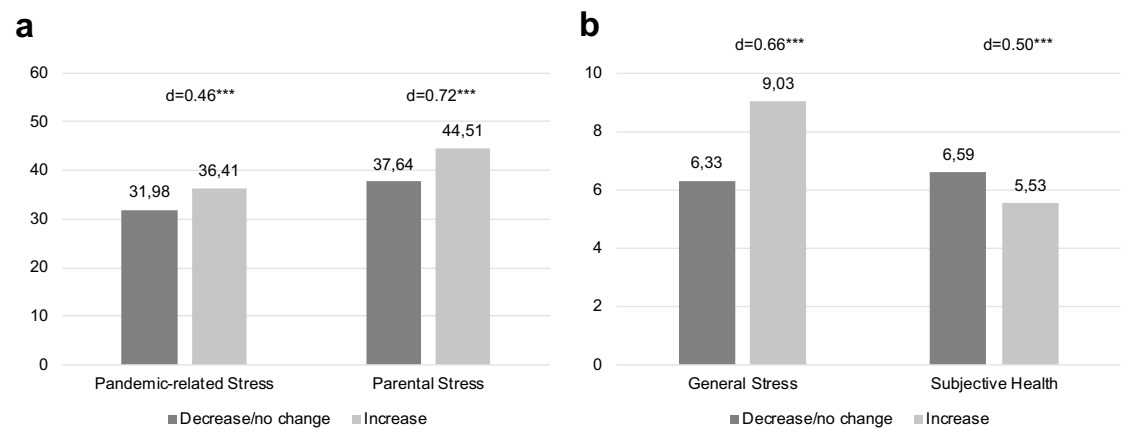

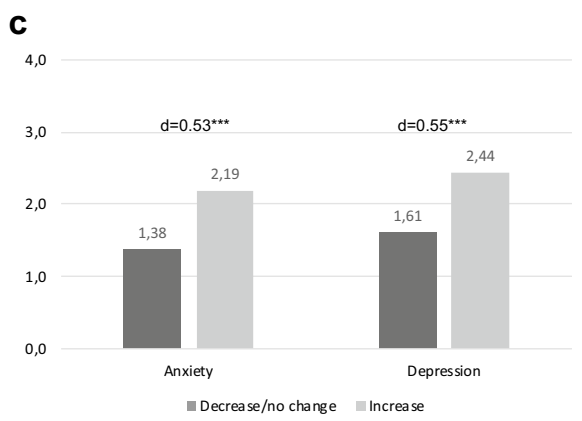

Fig. 4 Comparison of outcome measures in cases where frequency of witnessing domestic violence increased vs. decreased/did not change during the pandemic for a pandemic-related stress and parental stress, b general stress and subjective health, and c anxiety and depression. Cohen's $\mathrm{d}$ for effect size $(d=0.20$ : small, $d=0.50$ : medium, $d=0.80$ large); ${ }^{*} p<0.05, * * p<0.01, * * * \mathrm{p}<0.001$ 

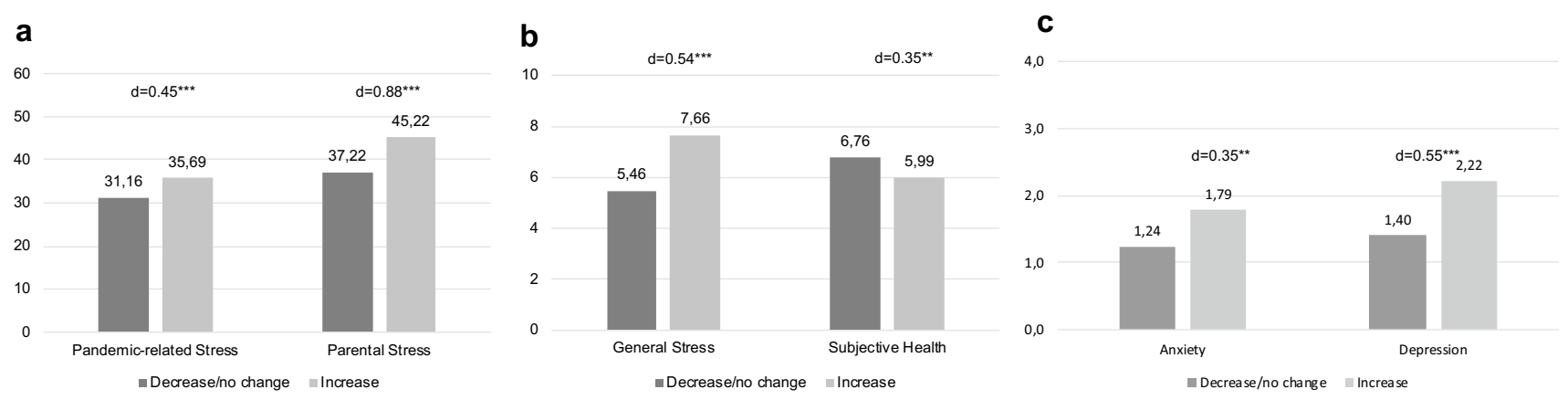

Fig. 5 Comparison of outcome measures in cases where frequency of verbal emotional abuse increased vs. decreased/did not change dur-

b general stress and subjective health, and $\mathbf{c}$ anxiety and depression. ing the pandemic for a pandemic-related stress and parental stress, Cohen's d for effect size $(d=0.20$ : small, $d=0.50$ : medium, $d=0.80$ : large); ${ }^{*} p<0.05,{ }^{* *} p<0.01, * * * p<0.001$

\section{Supplementary Materials}

For the supplementary materials, the revised tables are as follows:

Table S3 Bivariate correlations between the specific areas of pandemic-related stress and the outcomes on parent level

\begin{tabular}{|c|c|c|c|c|c|c|c|c|c|c|c|c|c|c|}
\hline & $\begin{array}{l}\text { Overall } \\
\text { burden }\end{array}$ & $\begin{array}{l}\text { Child- } \\
\text { care } \\
\text { closures }\end{array}$ & $\begin{array}{l}\text { School } \\
\text { closures }\end{array}$ & $\begin{array}{l}\text { Home- } \\
\text { work } \\
\text { online }\end{array}$ & $\begin{array}{l}\text { Work- } \\
\text { place } \\
\text { closures }\end{array}$ & $\begin{array}{l}\text { Working } \\
\text { from } \\
\text { home }\end{array}$ & $\begin{array}{l}\text { Maintain } \\
\text { daily } \\
\text { structure }\end{array}$ & $\begin{array}{l}\text { Social } \\
\text { distanc- } \\
\text { ing }\end{array}$ & $\begin{array}{l}\text { Restrict. } \\
\text { outside } \\
\text { activ }\end{array}$ & $\begin{array}{l}\text { Worries } \\
\text { own } \\
\text { health }\end{array}$ & $\begin{array}{l}\text { Worries } \\
\text { others' } \\
\text { health }\end{array}$ & $\begin{array}{l}\text { Restrict. } \\
\text { medical } \\
\text { treat- } \\
\text { ment }\end{array}$ & $\begin{array}{l}\text { Restrict. } \\
\text { psy- } \\
\text { choth. } \\
\text { treat- } \\
\text { ment }\end{array}$ & $\begin{array}{l}\text { Restrict. } \\
\text { child } \\
\text { services }\end{array}$ \\
\hline S & 25 & $235^{* * *}$ & & & & & & & & & & & & \\
\hline GS & $0.300^{* * *}$ & $.089^{*}$ & $0.290^{* * * *}$ & $317^{* * * *}$ & $261^{* * * *}$ & $0.292^{* * * *}$ & $362^{* * *}$ & $0.247^{* * *}$ & $232^{* * *}$ & $0.323^{* * * *}$ & $0.299^{* * * *}$ & $0.297^{* * *}$ & $0.339^{* * * *}$ & $0.298^{* * *}$ \\
\hline $\mathrm{SH}$ & & 0.0 & $-0.150^{* * * *}$ & $-0.191^{* * *}$ & -0.102 & $-0.199^{* * * *}$ & $-0.153^{* * * *}$ & & & $-0.293^{* * *}$ & $-0.201^{* * * *}$ & $-0.236^{* * *}$ & $-0.273^{* * *}$ & $-0.265^{* * *}$ \\
\hline ANX & $0.266^{* * *}$ & 0.077 & $0.227^{* * *}$ & $0.221^{\text {**** }}$ & $0.259^{* * * *}$ & $0.215^{* * *}$ & $0.240^{* * * *}$ & $0.193^{* * *}$ & $0.172^{* * * *}$ & $0.311^{* * * *}$ & $0.288^{* * * *}$ & $0.256^{* *}$ & $0.371^{* * * *}$ & $0.323^{* * *}$ \\
\hline DEPR & $0.283^{* * *}$ & $0.119^{* *}$ & $0.208^{* * *}$ & $0.244^{* * * *}$ & $0.175^{*}$ & $0.228^{* *}$ & $0.303^{* * *}$ & $0.222^{* * * *}$ & $0.226^{* * * *}$ & $0.236^{* * *}$ & $0.238^{* * *}$ & $0.228^{* * * *}$ & $0.317^{* * * *}$ & $0.236^{* * *}$ \\
\hline
\end{tabular}

Notes. $\mathrm{PS}=$ Parental stress; GS = general stress; $\mathrm{SH}=$ subjective health rating; ANX = anxiety; DEPR = Depression; for the subjective health rating, higher scores indicate better health, for the other outcomes, higher scores indicate higher burden, stress and symptoms; all parental outcomes with respect to the time of the subjectively highest burden; ${ }^{*} p<0.05$. ${ }^{*} p<0.01$. ${ }^{* * *} p<0.001$. 


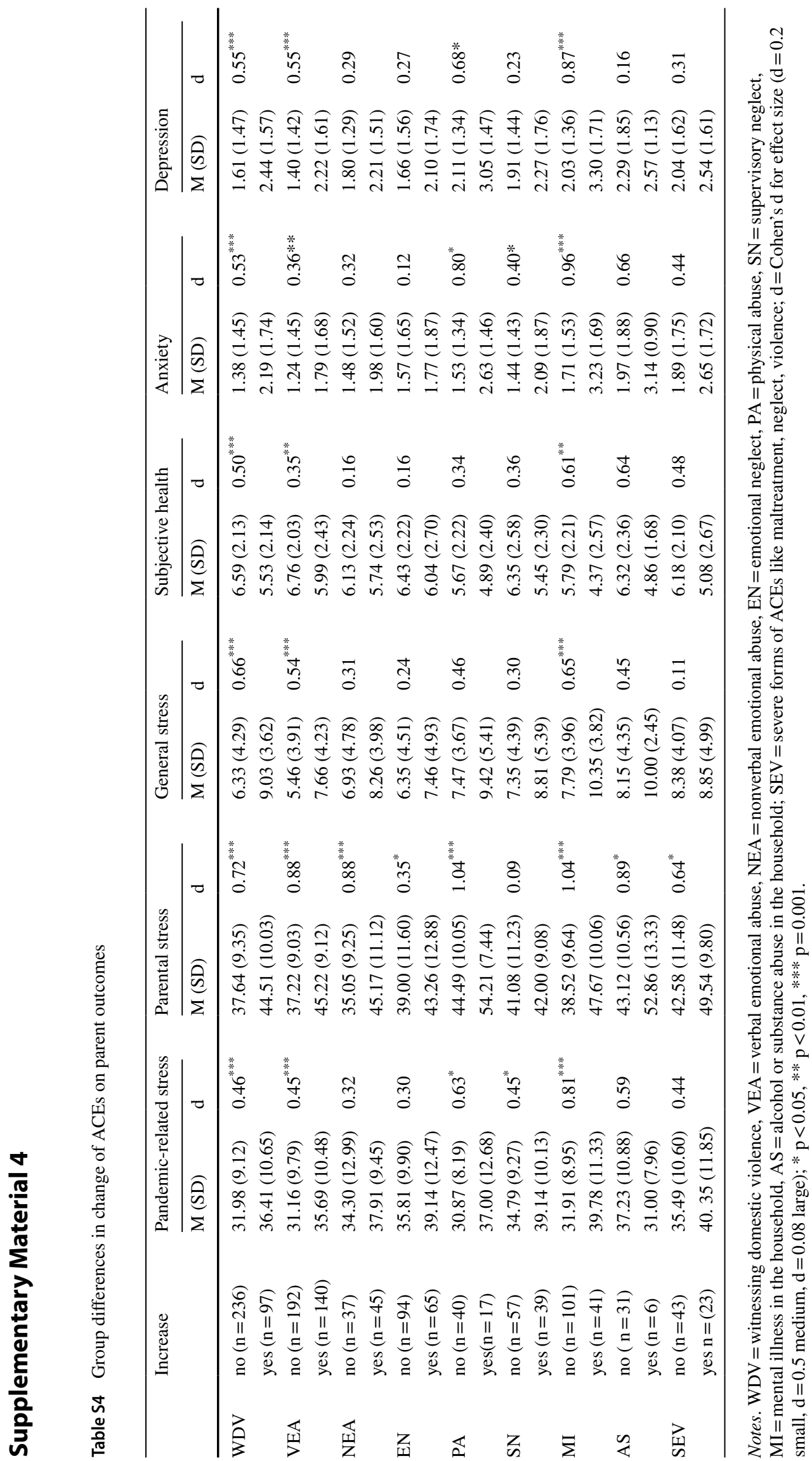

